Выхованец Алена Егоровна, Михельсон Ольга Константиновна

ПОПУЛЯРНАЯ МУЗЫКА И НОВАЯ РЕЛИГИОЗНОСТЬ: ВЗАИМОВЛИЯНИЕ РОК-МУЗЫКИ И

\title{
НАТИВИСТСКИХ ДВИЖЕНИЙ
}

Статья посвящена взаимовлиянию религиозности и феноменов популярной культуры. Оно рассматривается на примере связи современной популярной музыки жанров пейган-рок и фолк-рок с новыми религиозными движениями нативистского экологического типа, часто именуемыми неоязычеством. В работе обозначена такая особенность новой религиозности, как религиозный бриколаж, которая позволяет самым разным феноменам культуры стать источниками религиозных убеждений и опыта. Также анализируется лирика музыкальных коллективов, играющих в жанрах пейган- и фолк-рок, в которой использованы образы славянских дохристианских верований.

Адрес статьи: www.gramota.net/materials/9/2019/12/47.html

\section{Источник}

\section{Манускрипт}

Тамбов: Грамота, 2019. Том 12. Выпуск 12. С. 240-243. ISSN 2618-9690.

Адрес журнала: www.gramota.net/editions/9.html

Содержание данного номера журнала: www.gramota.net/materials/9/2019/12/

\section{( ) Издательство "Грамота"}

Информация о возможности публикации статей в журнале размещена на Интернет сайте издательства: www.gramota.net

Вопросы, связанные с публикациями научных материалов, редакция просит направлять на адрес: hist@gramota.net 


\section{Философия религии и религиоведение}

\section{Philosophy of Religion and Religious Studies}

УДК $1 ; 298.9$

https://doi.org/10.30853/manuscript.2019.12.47

Дата поступления рукописи: 15.11.2019

Статья посвящена взаимовлиянию религиозности и феноменов популярной культуры. Оно рассматривается на примере связи современной популярной музыки жанров пейган-рок и фолк-рок с новыми религиозными движениями нативистского экологического типа, часто именуемыми неоязычеством. В работе обозначена такая особенность новой религиозности, как религиозный бриколаж, которая позволяет самым разнылм феноменам культуры стать источниками религиозных убеждений и опыта. Также анализируется лирика музыкальных коллективов, играющчих в жанрах пейган- и фолк-рок, в которой использованы образы славянских дохристианских верований.

Ключевые слова и фразы: популярная музыка и религиозность; нативистские движения; религиозный бриколаж; пейган-рок; фолк-рок.

Выхованец Алена Егоровна

Михельсон Ольга Константиновна, к. филос. н.

Санкт-Петербургский государственный университет

a.vykhovanets@mail.ru; olia_mikhelson@mail.ru

\section{ПОПУЛЯРНАЯ МУЗЫКА И НОВАЯ РЕЛИГИОЗНОСТЬ: ВЗАИМОВЛИЯНИЕ РОК-МУЗЫКИ И НАТИВИСТСКИХ ДВИЖЕНИЙ}

Исследование поддержано грантом РФФИ, проект № 17-33-01128.

Религиозные и светские явления часто бывают тесно переплетены, более того, очевидно, что можно говорить о взаимовлиянии многих религиозных и секулярных культурных феноменов. Актуальность исследования обусловлена тем, что различные формы популярной культуры оказывают значительное влияние на жизнь современного общества, в том числе и на особенности современной религиозности, для которой характерен религиозный синкретизм или, точнее, религиозный бриколаж. Между тем этот вопрос до сих пор остается недостаточно изучен, особенно в нашей стране. Данное исследование призвано продемонстрировать взаимосвязь между популярной музыкой и религиозностью на примере новых религиозных движений экологического и нативистского толка, с одной стороны, и фолк- и пейган-рока - с другой.

Научная новизна исследования заключается в том, что, несмотря на все большее внимание научного сообщества к изучению взаимодействия религии и популярной культуры, в том числе и популярной музыки, влияние фолк- и пейган-рока (жанр популярной музыки, от англ. pagan - «языческий») на формирование интереса к дохристианским верованиям Древней Руси и появлению движений, пытающихся реконструировать «веру предков», пока не изучалось. В англоязычной научной литературе вышло несколько статей, рассматривающих так называемое «современное язычество» и популярную музыку. Эти работы в первую очередь анализируют западноевропейскую и американскую фестивальную культуру [15], влияние контркультуры на формирование так называемых неоязческих движений [11] и влияние фольклора на увлечение эзотеризмом в творчестве известных популярных музыкантов [14]. Однако ключевая исследовательница этого вопроса Д. Уэстон замечает: «Несмотря на то, что популярная музыка играет центральную роль в целом ряде культурных практик, очень мало академических исследований посвящено изучению ее взаимоотношений с современным язычеством» [16, р. 184]. Цель данного исследования - изучить, может ли интерес к фолк- и пейган-року влиять на формирование тех или иных религиозных взглядов. Поставленная цель обусловила необходимость решения следующих задач: кратко рассмотреть особенности современной религиозности, в первую очередь такое явление, как религиозный бриколаж; выделить и проанализировать славянские дохристианские образы, используемые в современном пейган- и фолк-роке; провести ряд интервью с поклонниками этих музыкальных стилей и проследить, существует ли взаимосвязь между их музыкальными предпочтениями и религиозными взглядами.

Современная религиозность весьма многолика, для нее характерно появление новых, эклектичных форм. Для обозначения этого феномена удачным представляется термин религиозный бриколаж, т.е. самостоятельное конструирование личных религиозных убеждений и практик на основе окружающих идей, объектов и явлений (от фр. bricolage - «сделай сам»), то есть склонность наполнять личную религиозную сферу 
различными концептами, идеями, ритуалами и т.д., которые «есть под рукой» и представляются привлекательными. Религиозный бриколаж предполагает, что различные элементы, причем как религиозные, так и изначально нерелигиозные, произвольно выбираются и комбинируются, причем подчас исключительно на индивидуальном уровне. Таким образом, можно заметить, что в современном религиоведении понятие бриколаж, изначально предложенное Леви-Строссом для определения особенностей первобытного мышления [6], было распространено и на особенности мышления человека, живущего в XXI веке [12].

Одной из заметных тенденций последних десятилетий является возникновение нативистских движений, которые пытаются «реконструировать» дохристианские верования, а их представители часто называют себя «язычниками» или «неоязычниками». В целом этому явлению присущ религиозный bricolage, поскольку религиозное вдохновение в данном случае черпается из самых разных источников. Возникновение этих движений связано с попыткой вернуться к некой исконной «религии предков», которая исповедовалась до христианизации (последнюю ряд адептов оценивают как чуждую и насильственную), с одной стороны, и с актуальной экологической платформой - с другой, поскольку «языческие» верования воспринимаются как религии, обожествлявшие природу и существовавшие с ней в гармонии.

Появление нативистских НРД или так называемого «неоязычества» - явление, характерное для многих регионов, в особенности для Скандинавии, Великобритании, стран Балтии и постсоветского пространства. Так, в России начало 90-х годов XX столетия ознаменовалось плюрализмом «духовного поиска» и всплеском новой религиозности, которой, в частности, был свойственен интерес к архаической культуре и религии Руси. Появилось множество объединений и движений, стремящихся возродить «веру предков» и пытающихся реконструировать дохристианские верования и культы, обрядовые и магические практики. Например, в 1989 г. в Москве формируется первая община, ставящая целью «возродить славянское язычество». Затем в 1991 г. в Ленинграде возникает «Союз венедов», после чего процесс распространяется и на другие регионы России [2].

Одновременно с развитием нативистских движений в России позднесоветского и постсоветского периодов набирают популярность музыкальные коллективы, которые заимствуют многие образы славянского фольклора и интерпретируют их в своем творчестве. Одна из первых рок-групп подобного рода, получившая широкую известность, - это «Калинов мост», основанная Д. Ревкиным в Новосибирске в 1986 г. Затем в конце 1990-х - начале 2000-х гг. под влиянием зарубежных, в частности скандинавских, фолк-рок и пейган-рок проектов появляются такие группы, как «Аркона», «Алконост», «Сварга», «Твердь», "Butterfly Temple”, «Северные Врата», «Темнозорь» и др.

Само название группы «Калинов мост» отсылает к славянской мифологии: калинов мост ведет через речку Смородинку и соединяет мир живых и мир предков, этот мост становится местом, где культурный герой должен победить хтоническое чудовище, чтобы защитить мир живых [7, с. 232]. Также в ранних текстах группы присутствуют аллюзии на славянскую историю, например, в композиции «Ранним утром» (1986) мы слышим: «Други-братья! Время цвесть боевому стягу! Время - через тьму пронесть нашу к Солнцу тягу! Точит зубы, скалит пасть лютых псов орава. С ними насмерть бой держать внукам Святослава!». Впоследствии, однако, Д. Ревякин, солист группы, отказался от своего юношеского увлечения славянской дохристианской тематикой и принял православие [3], что закономерно отразилось на его творчестве. Так, в песне «Родная» («Оружие», 1998) пожалуй, самой известной своей композиции - он изменил слова «инок, да шаман» на «инок, не шаман».

В 90-е гг. в России возникают такие музыкальные жанры, как викинг-метал (“NOMANS LAND”, «Tроль гнет ель») и славянский пейган-рок («Аркона», «Северные врата», «Темнозорь»), представители которых в своем творчестве также активно апеллируют к дохристианским образам. Важным фактором их становления стало распространение творчества скандинавских black metal групп, которые в своих произведениях использовали образы скандинавской мифологии (“Burzum”, “Mayham”, “Gorgoroth”, “Immortal”), и пейган исполнителей (Gwydion Pendderwen, “Inkubus Sukkubus”, “the Dolmen” и др.), напрямую связанных с новыми религиозными движениями, называющими себя языческими или неоязыческими.

«Темнозорь», российская пейган-метал группа, возникшая в 1996 г. в Обнинске, может рассматриваться как один из ярких примеров отечественного пейган-рока. Композиция «Диб-Дуб-Сноп» («Ведовством крепка чёрная слава Руси», 1998) звучит как гимн славянским богам: «Славься! Славься! Перун - Бог златокудрый! Он посылает стрелы во врагов, смелых ведет к победе. Славу поем мы ему и на пиру и в сечи. Славься! Славься! Сварог - Кузнец небесный! Он - отец всей поднебесной, он - смотритель вечный. Когда наш час придет, Он на лугах нас встретит». В композиции «Прославление павших» есть такие строки: «Взвейся птицей огнекрылой, разойдись, огонь священный, громче пойте Стрибога внуки, разнося по миру пепел бренный. Славя доблесть павших воинов, гусляры вам песни сложат, я же, жизнь за Русь отдавши, отхожу к лугам Сварожьим». Очевидно, что славянские дохристианские верования играют важную роль для создателей этих композиций.

«Аркона», группа, созданная участниками родноверческой общины «Вятичи» из Долгопрудненска в 2002 г., также была одной из первых, исполняющих музыку в стиле славянский фолк-металл. В том же году группа выпустила первые три трека: «Коляда», «Солнцеворот» и «Русь». Вот что говорит идейный лидер группы - Маша “Scream” Архипова - о своих религиозных взглядах: «Я живу по принципам, по которым могли бы жить далекие мне предки. Я уверена, что они не вешали на себя никаких ярлыков и жили в гармонии с природой по чести и совести, по правде и вере в себя и в то, что их окружает. Есть люди, которые придумывают для себя какие-то обычаи и правила, выдавая выдуманное за истинные каноны наших предков-славян, хотя они никогда не узнают, какими же обычаи были на самом деле. Мое мировоззрение выглядит иначе, не стремлюсь жить чужими мыслями, я стремлюсь познавать философию мира сама, без каких-либо книг и псевдопроповедников» [5]. Миссию своего творчества Мария видит в том, чтобы через музыку возрождать древнюю культуру, «традицию предков». Еще одна российская пейган-рок команда - «Северные Врата» - появилась в 1997 г. в Санкт-Петербурге. 
На ее творчество заметное влияние оказало движение «Схорон еж словен»: так, на альбоме «Правь» 2003 г. можно услышать композицию «Стрибог», а в песне «Кузница» с того же альбома есть такие строки: «Кием бьет Перун с плеча, держим правдой бой с врагом. Сполох мечет по холмам, требы к небу воздаем» [9].

Говоря о жанре фолк-рок в России, также следует выделить группу «Сколот», созданную в 2005 г. в Тамбове. Репертуар группы составляют авторские вокально-инструментальные композиции, основанные на русском, скандинавском и кельтском фольклоре. Создатели группы отмечают: «Мы верим, что фолк-музыка может не только дарить радость, но и помочь реализации потребности каждого человека в поиске своих истоков, самого себя, своего места в жизни и обществе» [10].

В ходе исследования было установлено, что увлеченность рок- и фолк-культурой, в частности, описанными выше коллективами, оказала влияние на формирование и трансформацию религиозных взглядов ряда адептов нативистских движений, что подтверждают глубинные интервью с поклонниками современной фолк-музыки, проведенные в рамках исследования. Респондент № 1 (мужчина, 40 лет, Санкт-Петербург), основатель одного из петербургских клубов исторической реконструкции, рассказал следующее: «В 90-е меня привлекли скандинавские black metal группы, у нас на тот момент ничего подобного не было. Сам я начал играть на гитаре, писать песни, записывал их в одиночку. Но фоне этого увлечения загорелся созданием клуба реконструкции эпохи викингов. Клуб был один из первых такого плана. Потом стал глубже изучать историю, понял, что у варягов и русов очень много общего, да и захотелось больше к родной истории обратиться. Начал осваивать русские музыкальные инструменты, музыку стал писать другую. Клуб тоже ушел в русской тему».

Схожую историю поведал респондент № 2 (мужчина, 37 лет, Санкт-Петербург), участник клуба исторической реконструкции, занимается кузнечным делом, исповедует «веру предков»: «Я, можно сказать, меломан, и мне нравятся скандинавские мотивы. Большой фанат Burzum, Immortal, Mayham. Но в блэке (black metal) ничего не разберешь. В 2012 г. начал слушать Аркону и дошел до народных инструментов, так узнал фолк, и тому способствовали гусли. В тот момент еще начал изучать горловое пение, потом пришел в клуб реконструкции».

Респондент № 3 (мужчина, 16 лет, Санкт-Петербург) учится в школе, о своем увлечении славянской культурой и религией заметил: «В начале 2019 г. познакомился с творчеством группы “Сколот” и благодаря их музыке заинтересовался славянской культурой, начал читать книги про богов, про обереги. Весной попал на живой концерт группы и был довольно сильно впечатлен! После концерта я понял, что я не один. Что есть гораздо больше людей, интересующихся своей национальной культурой. На фестивале познакомился с женщиной из петербургской родноверческой общины, увидел у нее фотографии с обряда "Комоедица", захотел сам принять участие в такого рода мероприятиях. Самостоятельно сшил себе славянскую рубаху». О значении музыки респондент добавляет: «Музыка - это истинные интересы человека, его психология. Если человек будет слушать добрые песни, то он и сам по себе будет добрым. Если говорить о фольклорной музыке, то благодаря ей формируется интерес к родному, к культуре».

Вот что говорит о значении музыки в его жизни респондент № 4 (мужчина, 24 года, Санкт-Петербург), участник родноверческой общины: «Музыка оказывает существенное влияние, она помогает лично мне прочувствовать дух времени. Музыкальные инструменты, как гусли или лютня, буквально переносят сознание. Музыка обязательна для изучения культуры, она может много чего сказать о людях того времени. Это лично моё мнение».

На примере данных интервью можно видеть, что популярная музыка обладает высокой степенью воздействия на человека и может повлиять на его мировоззрение, ценности и религиозные взгляды. Более того, музыка подчас сама выполняет часть функций, характерных для религии, в частности, она может являться источником религиозного опыта, когда, к примеру, концерт популярных исполнителей воспринимается как некое священнодействие. На концертах фолк- и пейган-рок коллективов, где часто собираются представители нативистских движений различных типов - родноверческих общин и участников клубов исторической реконструкции, а также музыканты, играющие на традиционных народных инструментах, - публика импровизированно самоорганизуется в круговые танцы (хороводы), бои, напоминающие бои «стенка на стенку», или имитирует действия гребцов на драккаре. Эти действия напоминают слэм (толчки и столкновения друг с другом) и мош (нанесение несильных ударов), характерные для рок-концертов. Как правило, они не имеют агрессивного характера, а создают особое эйфорическое состояние у участников процесса, что может повлиять на их дальнейшее увлечение «верой предков».

В настоящее время помимо групп, исполняющих музыку в жанрах фолк- и пейган-рок, появляется все больше коллективов, стремящихся воссоздать «аутентичное звучание» древнерусской музыки («Веданъ Колодъ», «Очелье сороки», «Стары Ольсы», «Разнотравье»). Музыканты этих групп используют только древние инструменты: бубны, варганы, гусли, волынки, кугиклы и др., тексты же могут быть записаны в этнографических экспедициях, а могут представлять собой авторскую стилизацию. Концертными площадками для таких групп преимущественно служат фестивали исторической реконструкции. Помимо непосредственного влияния на увлечение нативистскими движениями, можно отметить еще две важные функции фолкмузыки: она является своего рода маркером идентичности участников нативистских объединений и служит способом манифестации их убеждений.

Также следует подчеркнуть, что музыка служит важной частью многих новых религиозных движений, в том числе и нативистского, экологического толка. Характерным примером могут служить анастасийцы, или «Звенящие кедры России», для которых «такие действия, как пение песен и игра на музыкальных инструментах, сочинение и исполнение стихотворений, вождение хороводов, считаются обязательной составляющей полноценной жизни» [1, с. 233]. Идеи В. Мегре, лежащие в основе движения анастасийцев, повлияли на возникновение музыкального движения «Караван любви солнечных бардов». «Караван» представляет собой добровольное объединение музыкантов - исполнителей авторских песен, которые путешествуют по городам России и ближайшего зарубежья со своими концертами. Один из организаторов этого проекта, А. Самофал, 
рассказывает следующее: «Первый Караван Солнечных бардов стартовал в 2003 году - из Жёлтых Вод через Днепропетровск, Запорожье, Кривой Рог, Одессу. В нём было от 22 до 33 участников, и всем очень понравилось. Добирались, в основном, электричками. <.. > Караван - это другая цивилизация, много различных эмоций, событий, переживаний. А сколько новых людей встречается на пути! Каждый караванщик проживает свою жизнь ускоренной во много крат» [Цит. по: 8]. Участники движения воспринимают музыку как реальную силу, способную влиять на общество, распространять идеи добра, любви, жизни в гармонии с природой. Это отражено в одной из наиболее известных песен движения: «На планете миллиарды ждущих факелов в ночи, Доставай гитары, барды, души музыкой лечи. Мы встаём единым кругом, мир мечтой преображая. Шаг за шагом, друг за другом запоёт Земля большая» [4].

Исходя из изложенного, очевидно, что музыка используется участниками «Каравана» и как способ трансляции мировоззренческой позиции, и как маркер идентичности, поскольку «Караван любви солнечных бардов» и движение «Звенящие кедры России» непосредственно связаны между собой и объединяют людей со схожими убеждениями с помощью фестивалей («караванов») и других подобных мероприятий.

Таким образом, зарождение нативистских движений и развитие музыкальных жанров фолк и пейган рок происходят в России в один и тот же исторический период, часто именуемый периодом «духовного вакуума», связанного с поиском новой национальной идентичности в условиях кризиса советской идеологии. В конце 1980-х - 1990-е гг. музыканты начинают обращаться к образам дохристианской Руси, по-новому интерпретировать фольклорные сюжеты. С самого своего возникновения фолк- и пейган-рок, с одной стороны, и нативистские движения - с другой, оказываются в ситуации взаимного влияния: в музыкальном творчестве могут транслироваться идеи тех или иных НРД; она может являться маркером идентичности их участников. Параллельно музыка может влиять на формирование мировоззрения и увлекать нативистскими движениями. Более того, музыка и сама по себе подчас берет на себя некоторые функции, традиционно приписываемые религии, в частности, мировоззренческую, интегративную (коммуникативную) и компенсаторную, а также может выступать источником религиозного опыта [13].

\title{
Список источников
}

1. Андреева Ю. О. Представления о народных традициях в движении «Звенящие кедры России» // Аспекты будущего по этнографическим и фольклорным материалам: сборник научных статей. СПб.: МАЭ РАН, 2012. С. 231-245.

2. Гайдуков А. В. Славянское новое язычество в России: опыт религиоведческого исследования // Новые религии в России: двадцать лет спустя: материалы Международной научно-практической конференции. М.: Древо жизни, 2013. С. 169-180.

3. Дмитрий Ревякин («Калинов Мост») из язычества перешел в православие [Электронный ресурc]. URL: https://newsmuz. com/news_2_495.htm (дата обращения: 22.08.2019).

4. Доставай гитары, Барды! [Электронный ресурс] // Творческий центр «Кедры». URL: https://kedr.myl.ru/publ/11-1-0-48 (дата обращения: 01.09.2019).

5. Интервью с Марией Архиповой [Электронный ресурc]. URL: http://metalkings.ru/reviews/arkona/Arkona-rus2011.htm (дата обращения: 30.08.2019).

6. Леви-Стросс К. Первобытное мышление. М.: Республика, 1994. 384 с.

7. Пропп В. Я. Русская сказка: собрание трудов. М.: Лабиринт, 2000. 416 с.

8. Савельева С. Караван солнечных бардов [Электронный ресурс] // Быть добру: международная газета. 2008. № 12 (48). URL: https://gazeta.bytdobru.info/statya/64-karavan-solnechnyh-bardov (дата обращения: 01.09.2019).

9. Северные Врата: «Мы играем военный славянский метал» [Электронный ресурc]. URL: http://www.metallibrary.ru/ articles/interviews/161.html (дата обращения: 10.09.2019).

10. Сколот [Электронный ресурс]: официальный сайт. URL: http://www.skolot.ru/about-us (дата обращения: 30.08.2019).

11. Bennett A. Paganism and the counter-culture // Pop Pagans: Paganism and Popular Music / ed. by D. Weston, A. Bennett. L. - N. Y.: Routledge Taylor \& Francis Group, 2014. P. 13-24.

12. Hervieu-Léger D. Religion as a Chain of Memory. New Brunswick: Rutgers University Press, 2000. 204 p.

13. Partridge Ch. The Lyre of Orpheus: Popular Music, the Sacred and the Profane. Oxford: Oxford University Press, 2014.356 p.

14. Partridge Ch. The Occult and Popular Music // The Occult World / ed. by Ch. Partridge. L. - N. Y.: Routledge, 2015. P. 509-530.

15. Pop Pagans: Paganism and Popular Music / ed. by D. Weston, A. Bennett. L. - N. Y.: Routledge Taylor \& Francis Group, 2014. $288 \mathrm{p}$.

16. Weston D. Paganism and Popular Music // Religion and Popular Music / ed. by A. Häger. L.: Bloomsbury Academic, 2018. P. 184-197.

\section{POPULAR MUSIC AND NEW RELIGIOSITY: MUTUAL INFLUENCE OF ROCK MUSIC AND NATIVIST MOVEMENTS}

\author{
Vykhovanets Alena Egorovna \\ Mikhel'son Ol'ga Konstantinovna, Ph. D. in Philosophy \\ Saint Petersburg University \\ a.vykhovanets@mail.ru; olia_mikhelson@mail.ru
}

The article examines mutual influence of religiosity and popular culture. This problem is considered by the example of interrelation of modern pagan rock, folk rock and new religious movements of nativist ecological orientation often referred to as neopaganism. The authors reveal such a distinctive feature of new religiosity as religious bricolage, which considers cultural phenomena as sources of religious beliefs and experience. Lyrical pagan and folk-rock compositions applying to the Slavic preChristian images are analysed.

Key words and phrases: popular music and religiosity; nativist movements; religious bricolage; pagan rock; folk rock. 